\section{In Gedenken an Hans Falck (1923 - 2014)}

Denke ich an Hans Falck, so fällt mir sofort eine Schlüsselszene ein, in der sich wie in einem Brennglas seine biografischen, religiösen, politischen und wissenschaftlichen Bezüge bündeln.

„Am ersten Tag (des Passah-Festes 1945) sind wir von Frankreich nach Deutschland über die Grenze gefahren. Sobald wir innerhalb Deutschlands waren, haben wir unseren Jeep an der StraBe abgestellt und haben uns in einen Graben gesetzt, haben die $\mathrm{Pa}$ kete ausgepackt mit dem Passah-Essen, Matzen usw., und all den schönen Sachen, die uns geschenkt wurden als Soldat. Und da haben wir uns am ersten Passah-Tag - wir waren uns alle sehr, sehr bewusst um was es sich handelte, aber wir haben absichtlich gewartet bis wir innerhalb der deutschen Grenzen waren - in den Graben gesetzt und haben als ehemalige deutsch-jüdische Emigranten das Passah-Fest gefeiert. Und wenn ich daran denke, dann kommen mir heute noch die Tränen. Den anderen auch. Wir waren uns der Bedeutung dieses Aktes wahnsinnig bewusst, ganz besonders weil das Passah-Fest mit Befreiung und dem Auszug aus Ägypten zu tun hat“ (Schumann 1995).

Mehrfach hat Hans deutlich gemacht, dass dieses Erlebnis und die damit verbundene Erfahrung seinem ganzen weiteren Leben eine Richtung gegeben hat. Was Hans Falck, seine Familie und viele Andere übererlebt haben, war der historisch einmalige Versuch, einem ganzen Volk die Zugehörigkeit zur Menschheit abzusprechen und es deshalb umzubringen. Sein Buch über Membership widmet er auch den „sechs Millionen“, die in der Shoa ermordet wurden. Im Unterschied zu allen anderen furchtbaren Verbrechen des 20. Jahrhunderts, in denen Menschen als Feinde deklariert auf grausamste Weise umgebracht wurden, ging es im Nationalsozialismus darum, den Juden ihr Menschsein abzusprechen. Diese fundamentale Erfahrung der „Austreibung“ (wie Hans seine Vertreibung aus Hamburg nannte), hat ganz sicherlich zu dem fast axiomatischen Grundsatz seiner Membership Theorie beigetragen: „Membership ist permanent. Es kann nicht aufgehoben werden“ (1997:23) Diese anthropologische Grundannahme konkretisiert Hans in dem ersten Merkmal des Memberships, der ständigen und konstanten Verbundenheit der Menschen untereinander. Mit diesem Grundsatz formuliert Hans Falck eine Alternative zum westlichen Individualismus. Das bewegende Passah-Erlebnis macht aber auch deutlich, dass jede Form und jeder Inhalt des „ständigen Verbundenseins“" anders ist und wesentlich von dem Kontext abhängig ist, in dem es handelnd hervorgebracht wird. In diesem Fall waren die besonderen Bedingungen im Sinne des „bedingten Zugangs“ die Tatsache, dass hier jüdische US-Soldaten ihr Membership in einem Land realisierten, das sie eben noch ermorden wollte. Beide Komponenten des Memberships - ständige Verbundenheit und bedingter Zugang - kommen also immer nur zusammen vor.

Auf diese Weise formuliert Hans eine zukunftsweisende Perspektive der Sozialen Arbeit. Soziale Arbeit bildet danach eine

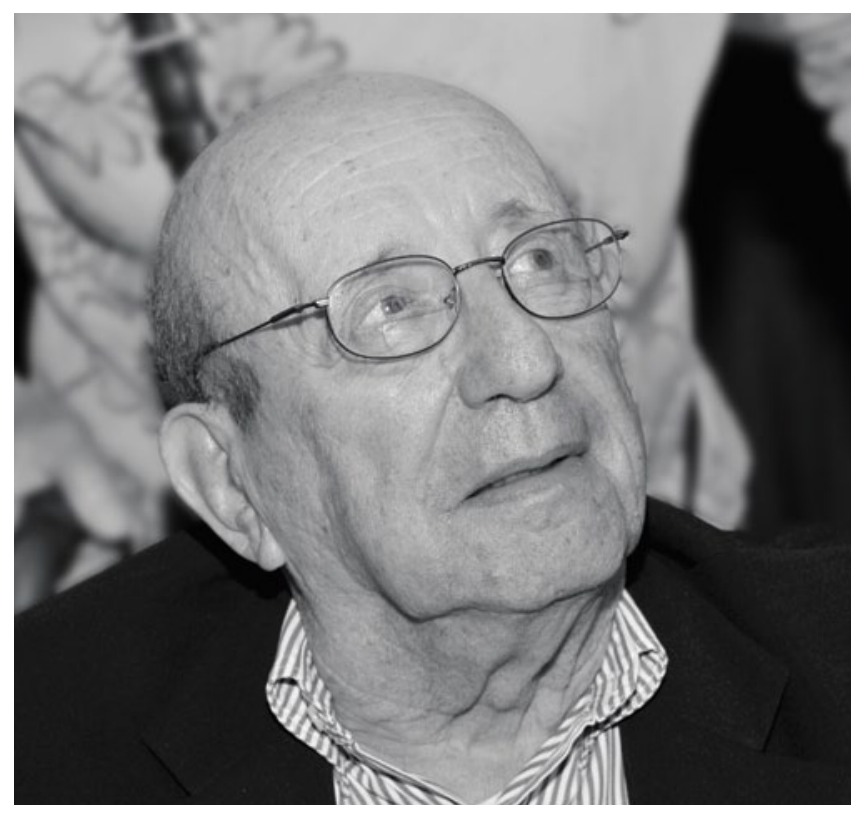

HANS FALCK (1923 - 2014).

Foto: privat

Brücke zwischen der frühen Erscheinung des Individualismus besonders im Christentum - und der hochentwickelten Version, die das moderne Leben heute bestimmt. Darin sind vier Aspekte oder Charakteristika eingeschlossen, die zusammen gesehen das Individuum definieren: das Unteilbare (indivisibility), das Einzigartige (uniqueness), das Selbstbestimmte (self-determinative) und das Autonome (autonomy), wie Hans in seiner Antrittsvorlesung zu seinem Gastsemester an der Universität Siegen 1996 ausführt.

Die jüdische Tradition der Gemeinschaftlichkeit gibt diesen Charakteristika eine besondere und erweiterte Bedeutung. Aus der Unteilbarkeit des Individuums wird ein Zugehöriger, der von sich abgibt und der vom Anderen annimmt, beides als Erfüllung fundamentaler Lebensbedingungen. Aus Einzigartigkeit wird die aktuelle Anerkennung, in der jedes Mitglied seine Zugehörigkeit anderen gegenüber und mit ihnen zusammen darstellt. Mit Zuversicht entdecken Menschen ihr Verwandtsein; aus individuellem Selbstbestimmungsrecht wird die soziale Selbstbestimmung, in der die Interessen des einen mit denen anderer verhandelt und auf die gemeinsam Bezug genommen wird. Aus Autonomie wird die Fähigkeit, als soziales Selbst zu handeln, indem die Konsequenzen der eigenen Pläne für andere transparent werden. Das „Ich“wird anstatt eines persönlich geheimnisvollen (aber auch isolierten) zu dem eines Zugehörigen; und Zugehörigkeit beschreibt das Ich im Du wie das Du im Ich - und beides zusammen im Wir.

Lieber Hans, für die Zugehörigkeit zu Dir danke ich Dir.

\section{Timm Kunstreich}

Schumann, M. (1995). Plädoyer für eine Sozialarbeitswissenschaft, in: Wieler/Zeller(Hrsg.), Emigrierte Sozialarbeit. Portraits vertriebener SozialarbeiterInnen, Freiburg 